\title{
Design System Development for a Fuel Cell Centrifugal Compressor
}

\author{
Cheng Xu' ${ }^{1}$, Lei Chen ${ }^{2, ~ *, ~ R y o i c h i ~ A m a n o ~}{ }^{1}$ \\ ${ }^{1}$ Department of Mechanical Engineering, University of Wisconsin-Milwaukee, Milwaukee, USA \\ ${ }^{2}$ Department of Architecture, University of South China, Hengyang, P. R. China \\ Email address: \\ xuc2@asme.org (Cheng Xu), 44308479@qq.com (Lei Chen), amano@uwm.edu (R. Amano) \\ ${ }^{*}$ Corresponding author
}

\section{To cite this article:}

Cheng Xu, Lei Chen, Ryoichi Amano. Design System Development for a Fuel Cell Centrifugal Compressor. International Journal of Fluid Mechanics \& Thermal Sciences. Special Issue: Fluid Mechanics \& Thermal Sciences in Turbomachines. Vol. 5, No. 4, 2019 , pp. 96-101. doi: $10.11648 /$ j.ijfmts.20190504.12

Received: September 22, 2019; Accepted: October 22, 2019; Published: November 5, 2019

\begin{abstract}
Centrifugal compressors have been used in many areas of the machinery. The centrifugal compressor design is very complex, and a unique design system needs to be developed. A centrifugal compressor design system should be easy to use in interface and also flexible for inputs and outputs. The design tool also needs to be able to predicate the compressor performance in a fairly accurate level. In this study, a centrifugal compressor design system which was developed in the past is further improved and developed. Current design system includes initial parameter studies, meanline analysis, throughflow calculation, impeller design, diffusser design, volute design, and structure analysis. The main improvements of the design system are adding the interface to allow users easy to use, adding the input and output capabilities and modifying few correlations. Current design system can predict the blade loading and compressor performance better compared with original design system. A fuel cell low flow and low specific speed centrifugal compressor is designed by using current design system and the prototype compressor is built. The compressor performance tests were conducted. The experimental results are compared with numerical analysis. The experiments are in good agreements with calculations. The results demonstrate that the centrifugal compressor design is successful and the design system can be used for the future centrifugal compressor designs.
\end{abstract}

Keywords: Turbomachinery Designs, Computational Fluid Dynamics (CFD), Centrifugal Compressors, Low Flow and Low Specific Speed Compressors

\section{Introduction}

Turbomachines have two categories based on their functions: compressors and turbines. Compressors absorb energy to increase the fluid pressure or head. Compressors are widely used in many industries, for example, power generation, oil and gas, petrochemical, aerospace, and automobile [1-9]. Turbines, in another aspect, produce the power by expanding fluids through drop pressure or head, and temperature. Turbines are widely used in aerospace, power generations, automobile, and aerospace, etc. Successful turbomachine designs are very critical. In the concept design stage of the turbomachines, it is very important to have a good estimation of the compressor or turbine performance from choosing preliminary parameters $[10,11]$. In these studies, the interfaces were added to the design system that previous developed by using FORTRAN codes. Some bugs were fixed and some calculations were improved by adding some of the research results [12].

The development of fuel cell technologies and improvements in fuel cells power densities make fuel cells possible to use in automobiles. With the reduction of the climate-changing, emission standards for on-road and non-road vehicles and engines, the fuel cell powered vehicles become one of the promising solutions. The fuel cell converts the chemical energy of a fuel and an oxidizing agent into electricity through a pair of reactions. For example, the hydrogen combines with oxygen from the air to produce electricity and releases water in a hydrogen fuel cell. The design of fuel cell systems is complex, and can vary significantly depending on fuel cell types and applications. 
The basic components of a fuel cell system are fuel cell stack, fuel processor, air system and power conditioners. Air system strongly affects the fuel cell stack efficiency and the parasitic power consumption. It is necessary to develop a clean, reliable, cost-effective oil-free air system [13]. Fuel cell performance improves as the reactant gases pressure increases. Fuel cells applications need pressurized air from atmosphere. A compressor in a fuel cell air system is used to increase the air pressure. The compressor normally needs to have a capacity to raise the pressure from 2 to 4 times of the ambient pressure. The development of a compressor with high efficiency and wide operating range is very critical to the fuel cell system.

In the fuel cell system, the reactants need to be delivered with the right pressures and flows. The high air system efficiency can reduce parasitic loads. One of the largest parasitic load in a fuel cell system is caused by air compressors. Several different technologies are being explored to fill the needs of fuel cell air compressors. The twin-screw compressors and centrifugal compressors are widely used in the fuel cell air systems. The twin-screw compressors are noisy and require lubrication during the operation. The centrifugal compressors have relative poor turn-down and need a high-speed motor to drive them [10]. The centrifugal compressors have better efficiency than twin-screw compressors. With the progress of the variable speed high-speed motor, the centrifugal compressors provide a promising future for fuel cell air systems.

In a vehicle fuel cell air system, it normally requires air with volumetric flow in the range between 30 to $500 \times 10^{-3} \mathrm{~m}^{3} / \mathrm{s}$ at vehicle operating conditions. The most high-speed motor can not meet the compressor flow coefficient requirements for best centrifugal efficiency for a single stage compressor; the compressors mainly operate at low flow coefficient range. For a low flow coefficient centrifugal compressor stage, the compressor efficiency is low due to dissipation in the flow path, more leakage and windage losses. A low flow coefficient unshrouded centrifugal compressor impeller has a relatively large clearance due to small blade height at impeller exit. The large tip clearance can cause flow separations, as a result it drops both the efficiency and surge margin. The design of a low flow coefficient centrifugal compressor with high efficiency and wide operation range is challenge.

This paper presents a new development of high efficiency and large surge margin low flow coefficient and low specific speed centrifugal compressor for fuel cell applications. In this study, a centrifugal compressor design system developed in the past are further improved [11] to use for this compressor design. The user interfaces have been added in the compressor design system. The upgrade system is also built the function that can design the tip clearance arbitrary. The functions for output design data to different design systems are added.

In this low flow compressor design, the non-linear tip clearance is used to allow impeller insensitive to the tip clearance. In order to have a wide operation range of the compressor, vaneless diffuser is used in this design. It is demonstrated that the design is in great success. The compressor design system can be used for future centrifugal compressor designs. The current design has been analyzed and a prototype unit is built and tested. Test results demonstrated that the design meets the customers' needs.

\section{Compressor Design System}

The design system needs to include all component designs and performance estimations. Centrifugal compressors typically consist of an impeller, diffuser, and volute or collector. The current design system and design process are shown in Figure 1. The design system is a direct design base system [11]. The compressor direct design process typically requires more time in the aerodynamic and structure interactions, but it can generate more accurate designs to meet the manufacturing requirements. Direct design can also easily to reach the structured target. In the design iteration, all designs are evaluated by aerodynamic and structural integrity as well as manufacturing capability. The final design is the results of design optimization. One-dimensional meanline code had been developed to estimate the compressor performance maps. In current studies, the technology performance adders were added into the meanline calculations to consider the potential efficiency gains from three-dimensional designs as well as new manufacturing technologies. A two-dimensional meridional analysis flow solver was developed with an inviscid governing equations to solve for meridional flow field. In this studies, the viscosity effects were added to the code in order to predicate the flow field and blade loading more accurately [12].

The detail geometry design consists four parts: impeller design (Design), impeller scale (SC), vane and scroll design as shown in Figure 2. The main improvements of the design system are user interfaces and add more input and output functions in the design system. The design system is more flexible and easy to use. The impeller can be designed based on the one-dimensional optimization results or scaled from existing impellers based on the design targets. The compressor diffuser and scroll can also be created based on the designers' parameter inputs or system default design based on the impeller parameters and stage design targets. The design system has been improved to be able to output design data to CFD tools and CAD systems.

The design of the impeller is very critical for a compressor stage. The proper blade loading distributions with minimums boundary layer distortions can significantly improve the compressor performance. The estimations of the blade loadings are improved in the current studies to more close to CFD results. Many design optimizations and CFD analysis have been used for improving the impeller aerodynamic designs [13-21]. Impeller aerodynamic design not only affects the impeller efficiency but also affects the performance of downstream diffuser and volute. It is important for an impeller to achieve a high-efficiency design with relative uniform exit flow. The design of centrifugal impeller is subject to multidisciplinary and multi-objective optimizations among aerodynamics, structure, and rotor dynamics. In this study, a design system developed in the past is further improved. A 
low flow coefficient and low specific speed fuel cell centrifugal compressor design is performed by using current design system [11].

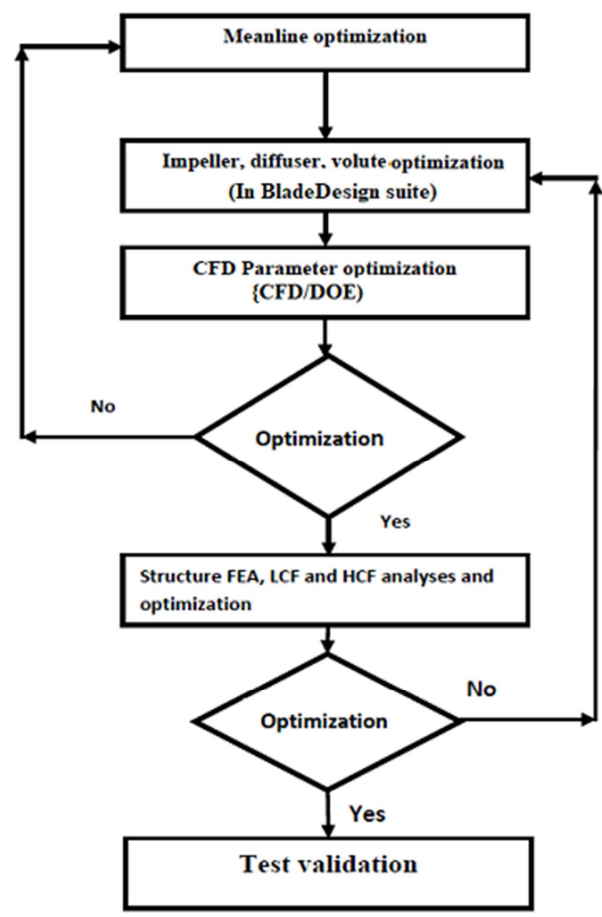

Figure 1. Centrifugal compressor design process.

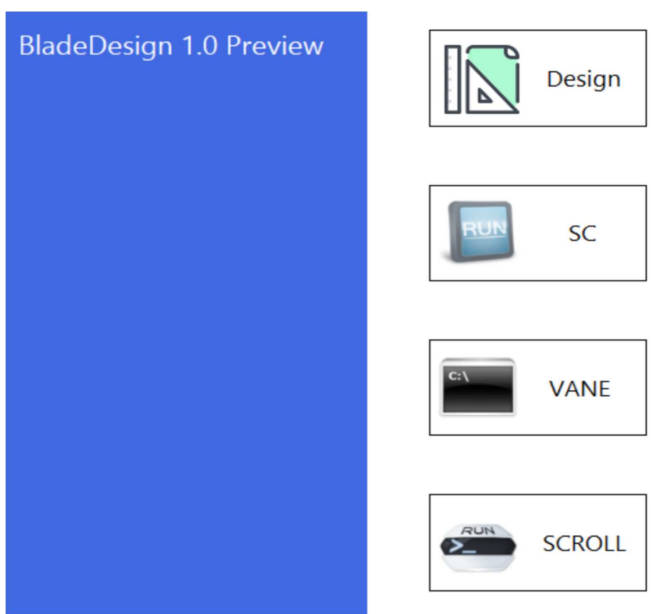

Figure 2. In-house centrifugal compressor design system.

The basic function of the impeller design tool is as shown in Figure 3. The impeller design tool consists three major parts: impeller blade meridional design, blade angle design, and blade thickness design. The tool can display the impeller blade meanline shape for designers' references. The newly developed interface makes it easy for designers to perform impeller design. The tool can be used for diffuser vane and axial turbomachine designs. The design tool can perform comparisons for different design iterations. The impeller geometry data can output into CFD and CAD tools. The three-dimensional impeller display is still under development.

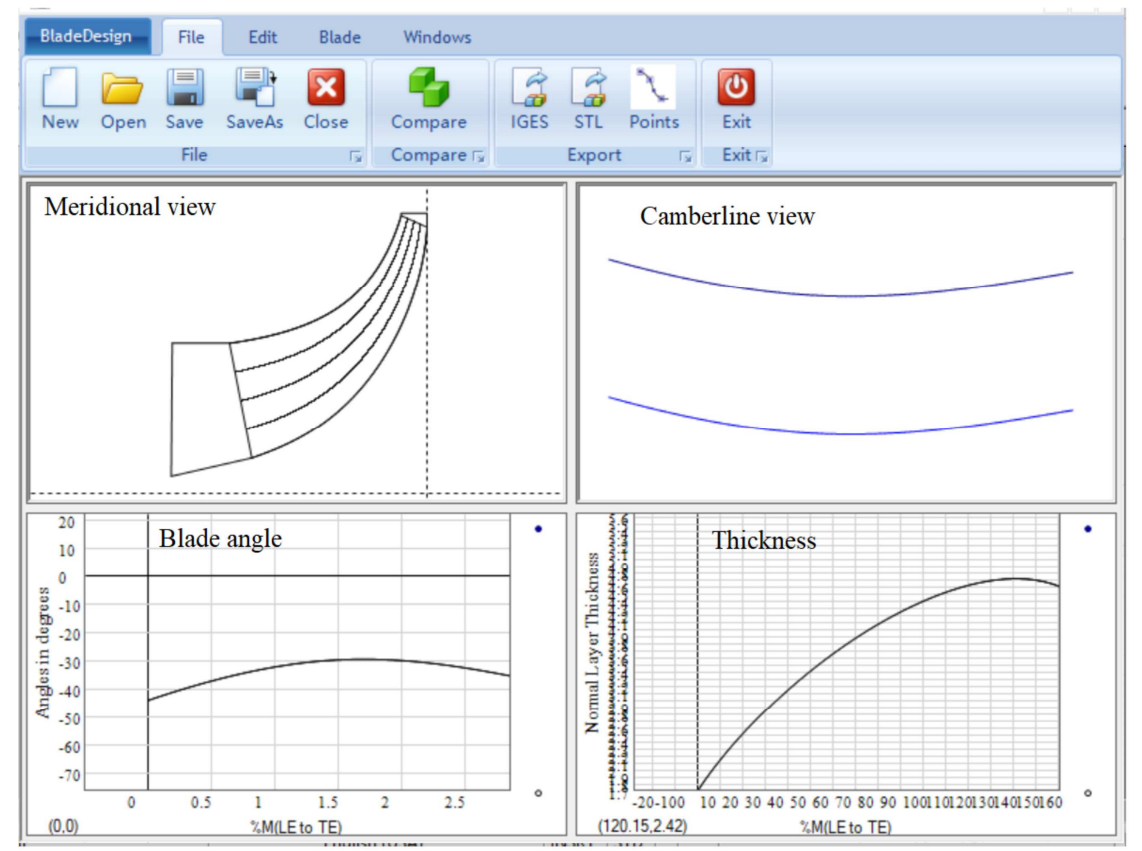

Figure 3. Blade design tool.

CFD has been widely used in aerodynamic studies and designs [14-21]. The application of CFD is an essential part of the centrifugal compressor design. The flow field in a centrifugal compressor contains both primary and secondary flows at the exit of the impeller. The flow entering the diffusor is unsteady, and it has high kinetic energy at inlet. This high level of dynamic pressure will convert to static pressure at exit of the diffuser. The non-uniformity of the pressure caused by the volute influences the flow fields in the diffuser. The oneand two- dimensional tool can not provide detail flow field information even technology adders were added in the design code to fairly good to estimate the compressor performance. 
CFD is used as a tool to perform compressor stage analyses and further optimize the centrifugal compressor performance during the compressor design [14-21].

A low flow coefficient centrifugal compressor was designed to meet the fuel cell air system's needs. A high-speed motor was developed for this application. The compressor was directly driven by a high-speed motor and compressor can operate at any speed within motor stable working range. The motor operating speed range is from $10 \mathrm{krpm}$ to $110 \mathrm{krpm}$. Because fuel cell application needs $100 \%$ oil-free, air bearings are used. The maximum fuel cell air flow is at maximum torque of engine when vehicles operate at highest altitude. The fuel cell maximum flow point on the operating line, called lug-line, most of the time is also the highest pressure ratio point for fuel cell air system.

For performing the compressor design, we have to choose an operating point as a design point. In this study, inlet total pressure and temperature were $85 \mathrm{kpa}$ and $311.15 \mathrm{~K}$ for design inlet conditions. The inlet mass flow rate and pressure ratio are $46 \times 10^{-3} \mathrm{~kg} / \mathrm{s}$ and 2.0 respectively. At compressor aerodynamic design point, the impeller rotational speed is 95.5Krpm. The compressor flow coefficient 0.087 and specific speed $\mathrm{N}_{\mathrm{s}}=0.46$. The target adiabatic efficiency according to customer's request is $70 \%$ at compressor design point. This target efficiency directly impacts the engine maximum torque level at high altitude. The higher the compressor efficiency, the more powerful fuel cell power can provide.

\section{Compressor Design}

For meeting the design point performance targets and fuel cell operation needs, the compressor must have a wide operating range. To design a low flow coefficient compressor to meet the design goal is very challenge, especially the wide operating range. Two factors limit the overall operating range of a centrifugal compressor: surge margin and overload capacity. The surge or stall margin limits the compressor's ability to operate at flow rates lower than design flow, while overload capacity limits the ability to operate at higher rates. For a fuel cell air system, design a compressor for have a good operating margin for surge or stall margin is critical.

The impeller blade loading distributions are very critical for the success of the low flow centrifugal compressor design. In this design, the compressor impeller was designed with eight blades and eight splitters in order to have high efficiency and wide operating range. The blade loading at mid-span of the full blade and splitter is shown in Figure 4. It can be seen that the blades loading is fairly uniformly from leading edge to trailing edge. The blade loading is slightly higher before $95 \%$ of the meridional location. At near the exit of the impeller, it loads slightly lightly than other location to make sure the compressor has a good surge margin. The nonlinear tip clearance is used for the gap between impeller shroud and casing in order to reduce the tip clearance loss and further improves the compressor operating range. The tip clearance distribution from compressor inlet to exit is shown in Figure 5.
The nonlinear clearance can improve the compressor performance and operating range [2]. In this design, the clearance is relative smaller near the middle of the meridional location. The structure analysis demonstrated that the deformation at the middle of the impeller is away from compressor casing. When impeller rotating, the clearance at the middle of the meridional gets bigger than the clearance when impeller is installed. Making this location with minimum clearance not only can improve the performance but also operates safely from structure point of view.

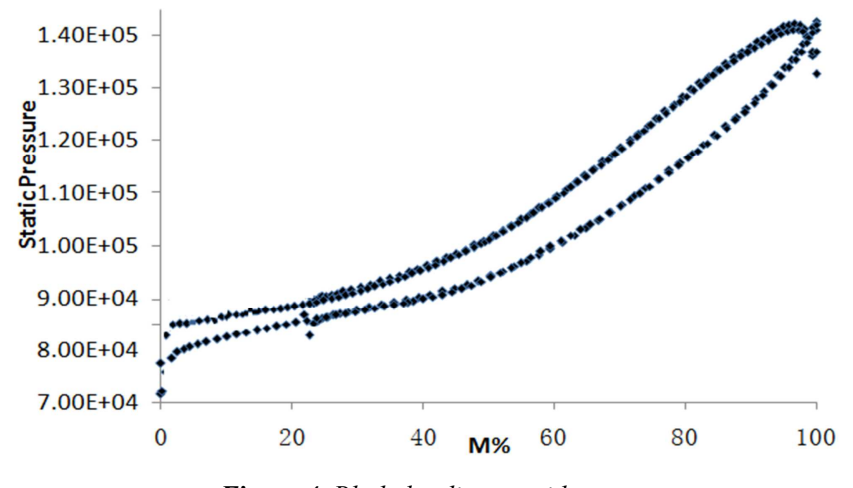

Figure 4. Blade loading at mid-span.

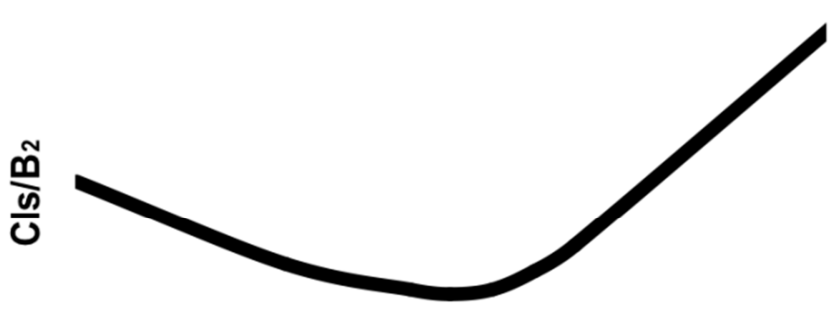

$\mathrm{M} \%$

Figure 5. Tip clearance distribution alone the impeller shroud.

In this compressor development, we started with a parametric optimizations by using meanline studies, through flow analysis, then the impeller and scroll design. CFD is used to calculate compressor performance and optimize final designs [17-22]. At the same time, the impeller stress, vibration frequencies, HCF and LCF life calculations are performed [20, 22] to make sure that the compressor is reliable. In this way, the final design is optimized for both aerodynamics and structural aspects. The volute design is based on the conservation of the momentum and the conservation of mass [4-7]. A high backward exit angle of the impeller was used in this design to improve the efficiency by reducing the impeller loading and enhance the surge margin. The final compressor stage CFD analyses were performed by using commercial software Ansys [22]. The analytical results are compared with tests.

For demonstrating the performance of the current design, two high-speed motors and three units of compressor prototypes were built for aerodynamic tests. The compressor and motor assemble is shown in Figure 6. The compressor performance tests were conducted at the development laboratory. The part inspections showed that the 
manufacturing variations of all compressor parts are within specifications. A compressor using parts with less manufacturing variations was assemble to do performance test. The test system uncertainty analysis was performed. The test uncertainty for efficiency measurement is $\pm 0.35 \%$ due to thermal couple and pressure transducer uncertainties. The inlet flow measurements are based on the orifice plate installed at the discharge of the compressor. The volumetric flow measurement uncertainty is $\pm 1.0 \%$. The pressure ratio measurement uncertainty is $\pm 0.1 \%$ at design pressure ratio. The rotational speed measurement uncertainty is 1 RPM.

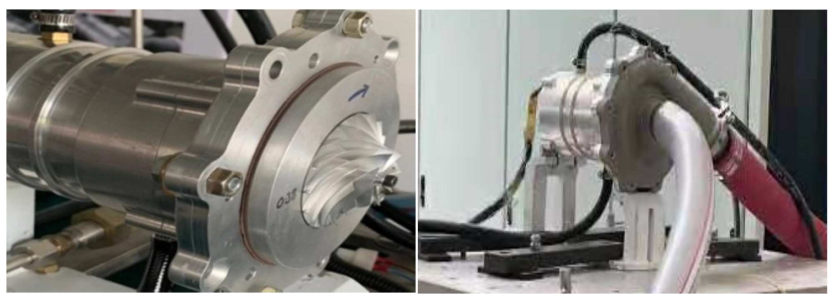

Figure 6. Prototype compressor and motor.

The mesh independent studies were performed before the final mesh size was chosen for CFD studies. The hexahedral mesh was used in this study as shown in Figure 7. The mesh sizes are approximately 1.5, 0.5, 1.7 million nodes for impeller, vaneless diffuser and scroll respectively. The compressor stage ratios calculated from CFD at different rotating speeds are compared with experiments as shown in Figure 8. The compressor operating lines in a fuel cell system or called luglines at sea level and maximum vehicle design altitude are also plotted in the figure. It is shown that two luglines of the fuel cell compressor are well within the compressor map. In order to provide similar torque for vehicle at high altitude comparing with sea level, the compressor needs to operate at higher pressure ratio and volumetric flow. The high altitude compressor lugline moves toward to up right side of sea level lugline. The compressor map showed that the compressor had enough operating range to cover all the fuel cell operation points. The compressor performance tests were performed at three different rotating speeds. It is shown that the calculated compressor ratios are in good agreement with experiments. The compressor isotropic efficiencies at different rotating speed at different flow coefficients are shown in Figure 9. The compressor efficiency data from experiments for three-speed lines showed that experimental efficiencies levels slightly higher than calculated efficiencies. It is also shown that the compressor performances are slightly better than design targets for both efficiency and operating range.

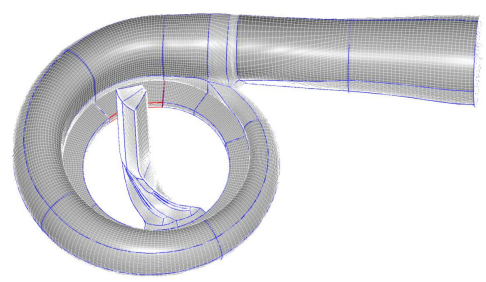

Figure 7. Computational Mesh.

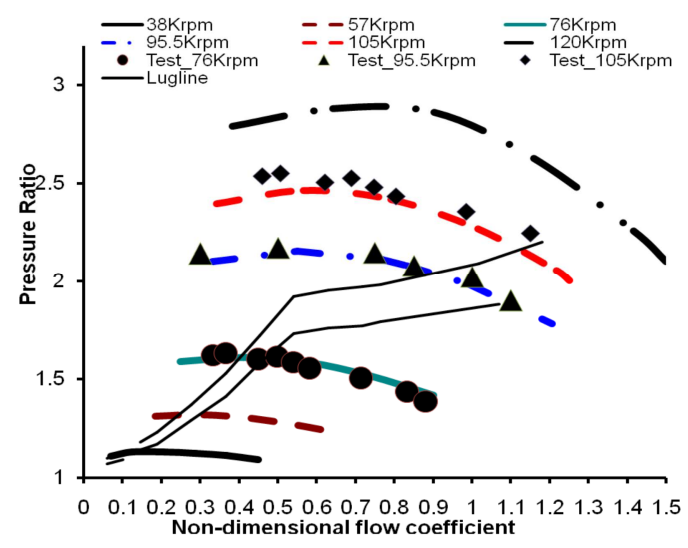

Figure 8. Pressure ratio Vs non-dimensional flow coefficient.

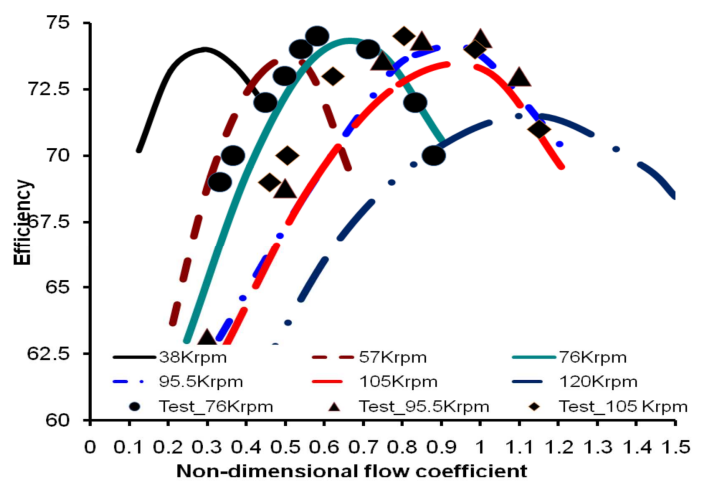

Figure 9. Adiabatic efficiency Vs non-dimensional flow coefficient.

\section{Conclusions}

In this study, the in-house compressor design system was further improved. Several calculation codes were re-calibrated and checked. Some research results were added to the design system to improve one dimensional calculations. The improved meanline code can predict the blade loading more accurately than original one. The design code user interfaces were developed for user-friendly. The new capabilities for data output and input between the design system and other CAD system were added. This design system was used to develop a fuel cell low flow coefficient and low specific speed centrifugal compressor. The successful design of the low flow centrifugal compressor verified the design system. The further calibrations of the design system are still needed for other type of compressor designs.

A low flow coefficient and low specific speed centrifugal compressor was developed for fuel cell applications. The studies demonstrated that the impeller blade loading, impeller exit blade angle and tip clearance optimizations can improve the compressor performances. The high-speed motors and compressor prototypes were built for performance tests. The experimental results demonstrated the centrifugal compressor stage performance was slightly better than design requirements. The on-vehicle road tests for the compressor system need to be performed to make sure the compressors and motors are reliable. The on-vehicle road tests will also provide the information on the compressor performance degradation. 


\section{Nomenclatures}

$\begin{array}{ll}\text { B2 } & \text { Impeller exit blade width } \\ \text { CAD } & \text { Computer-aided design } \\ \text { CFD } & \text { Computational Fluid Dynamics } \\ \text { cls } & \text { Impeller shroud tip clearance } \\ \mathrm{D} 2 & \text { Impeller exit diameter } \\ \mathrm{H} & \text { Head } \\ \mathrm{M} & \text { Meridional non-dimensional distance } \\ \mathrm{N} & \text { Impeller rotational speed } \\ \mathrm{N}_{\mathrm{s}} & \text { Specific speed, }=\mathrm{NQ} \mathrm{Q}^{0.5} / \mathrm{H}^{0.75} \\ \mathrm{Q} & \text { Inlet volumetric flow } \\ \phi & \text { flow coefficient, }=\mathrm{Q} /\left(\mathrm{ND}_{2}{ }^{3}\right)\end{array}$

\section{References}

[1] R. H. Aungier, Centrifugal Compressors: A strategy for Aerodynamics Design and Analysis, ASME, Press, New York, USA, (2000).

[2] C. Xu and M. Muller, The design and development of low solidity centrifugal compressor volute. (2006), International Journal of Rotating Machinery, 2006.

[3] C. Xu and R. S. Amano, Computational Analysis of Scroll Tongue Shape to Compressor Performance by Using Different Turbulence Models, International Journal for Computational Methods in Engineering Science and Mechanics, Vol. 11 No. 2, 85-99, 2010.

[4] C. Xu, H. Yang, Y. Jiang, and Z. Yi. The Development of an Integrally Geared Centrifugal Compressor. International Journal of Fluid Mechanics \& Thermal Sciences. Vol. 5, No. 1, (2019) 1-9. doi: 10.11648/j.ijfmts.20190501.11.

[5] C. Xu, Design Experience and considerations for centrifugal compressor development, Journal of aerospace engineering 221 (2007) 273-287. Proceedings of the institution of Mechanical Engineers, Part G: Journal of aerospace engineering, 221 (2), pp 273-287.

[6] C. Xu, R. S. Amano, Empirical Design Considerations for Industrial Centrifugal Compressors, International Journal of Rotating Machinery, 2012 (2012) 1-16.

[7] C. Xu, R. S., Development of a Low Flow Coefficient Single Stage Centrifugal Compressor, International Journal for Computational Methods in Engineering Science and Mechanics, 10 (2009) 282-289.

[8] C. Xu, R. S. Amano, The Development of a Centrifugal Compressor Impeller, International Journal for Computational Methods in Engineering Science and Mechanics, 10 (2009) 290-301.

[9] C. Xu, R. S. Amano, Study of the flow in a centrifugal compressor, Int. J. of Fluid Machinery and System, 3 (3) (2010), pp 260-270, 2010.3.3.260.
[10] M. G. Turner, A. Merchant, D. Bruna, A Turbomachinery Design Tool for Teaching Concepts for Axial-Flow fans, compressor, and Turbines, GT2006-90105, May 8-11, 2006, Barcelona, Spain.

[11] C. Xu, R. S. Amano, On the Development of Turbomachine Blade Aerodynamic Design System, International Journal for Computational Methods in Engineering Science and Mech, 10 (3) (2009), pp. 186-196, 10.1080/15502280902795052.

[12] C. Xu, Kutta condition for sharp edge flows, Mechanics Research Communications, Vol 25, No. 4, July 1998.

[13] S. Pischinger, C. Schönfelder, W. Bornscheuer, H. Kindl, A. Wiartalla, Integrated Air Supply and Humidification Concepts for Fuel Cell Systems, SAE Paper 2001-01-0233, SAE International, Warrendale, PA, (2001).

[14] C. Xu, R. S. Amano, Computational Analysis of Swept Compressor Rotor Blades," International Journal for Computational Methods in Engineering Science and $\begin{array}{llll}\text { Mechanics, } & 9 & \text { (6), } & \text { 374-382, }\end{array}$ $10.1080 / 15502280802365840$.

[15] C. Xu, R. S. Amano, Effects of Asymmetric Radial Clearance on Performance of a Centrifugal Compressor, ASME, Journal of Energy Resources Technology 140 (5), (2017), DOI: 10.1115/1.4038387.

[16] C. Xu, R. S. Amano, Centrifugal Compressor Performance Improvements Through Impeller Splitter Location, J. Energy Resour. Technol. 140 (5), (2017), doi: 10.1115/1.4037813.

[17] J. Gonzalez, J. Fernandez, E. Blanco, and C. Santolaria, Numerical Simulation of Dynamic Effects Due to Impeller-Volute Interaction in a Centrifugal Pump, ASME J. Fluids Eng., 124, (2002), 10.1115/1.1457452.

[18] R. V. Chima, A three-dimensional unsteady CFD model of compressor stability, ASME Turbo Expo 2006, Power for Land, Sea, and Air, pp. 1157-1168. American Society of Mechanical Engineers (2006).

[19] J. Denton, W. Dawes, Computational fluid dynamics for turbomachinery design, Proceedings of the Institution of Mechanical Engineers, Part C: Journal of Mechanical Engineering Science 213 (2), 107-124 (1998).

[20] H. P. Dickmann, T. S. Wimmel, J. Szwedowicz, D. Filsinger, C. H. Roduner, Unsteady flow in a turbocharger centrifugal compressor, Three-dimensionalcomputational fluid dynamics simulation and numerical and experimental analysis of impeller blade vibration. Journal of turbomachinery 128 (3), 455-465 (2006).

[21] C. Xu, R. S. Amano, Aerodynamic and structure considerations in centrifugal compressor design-blade lean effects, GT2012-68027 (2012).

[22] ANSYS Inc., Ansys version 15, ANSYS, Inc, 275 Technology Drive, Canonsburg, PA 15317, (2013). 